\title{
DEL AYOTE AL CULANTRO: EL CUERPO COMO IMAGEN CULINARIA EN LA TRADICIÓN POPULAR Y EN LOS CUENTOS DE CARMEN LYRA
}

\author{
Carlos Manuel Villalobos
}

\begin{abstract}
RESUMEN
En la tradición popular costarricense existe un amplio repertorio de metáforas culinarias, principalmente de frutas y vegetales, destinadas a representar distintas partes del cuerpo humano y ciertas emociones. En la comunicación que se propone se estudia el privilegio visual del cuerpo humano. Se toma en cuenta la tradición oral costarricense y se compara con la apropiación que hace la escritora Carmen Lyra de estas metáforas. Con base en la Semiótica de la Significación se analiza la fragmentación del cuerpo y los arquetipos eróticos y tanatológicos que se vinculan con este sistema discursivo.

Palabras clave: metáforas populares, literatura costarricense, discurso culinario, Lyra-Carmen.
\end{abstract}

\begin{abstract}
In the Costa Rican popular tradition there are a wide range of culinary metaphors, with fruits and vegetables. These products represents different parts of the human body and certain emotions. This article examines the visual privilege of human body in the oral tradition in Costa Rica. It compares the popular metaphors with the short stories by Carmen Lyra. This researching used the Semiotics of Meaning to examine the fragmentation of the body and erotic and thanatological archetypes and their relation with this discursive system.

Key words: Popular metaphors, Costa Rican literature, culinary discourse, Lyra-Carmen.
\end{abstract}

\section{Entrada: La construcción metafórica del cuerpo humano}

La imaginación manierista del pintor italiano Giuseppe Arcimboldo, (Milán 1527-1593), produjo una serie de curiosos bodegones, cuya composición muestra rostros humanos hechos a partir de productos naturales y otros objetos. Una de las pinturas más conocidas de este pincel exagerado es Vertumno (1590): un retrato hecho de vegetales, frutas, granos y flores.

Estas imágenes arcimboldianas propician una interpretación sui generis del ser humano y, en cierto grado paródica, pues sustituyen el pelo, la piel, los ojos y hasta la ropa por composiciones basadas en elementos u objetos naturales o de manufactura humana. Estas

Dr. Carlos Manuel Villalobos. Profesor catedrático. Universidad de Costa Rica.

Correo electrónico: carlos.villalobos@ucr.ac.cr

Recepción: 21- 03- 2013

Aceptación: 25- 04- 2013 
representaciones metafóricas coinciden con recurrencias del habla popular que igualmente sustituyen el cuerpo humano o partes de este por productos naturales o artificiales.

Por ejemplo, el cuerpo puede ser representado como metáfora mecánica, donde el corazón es un reloj y el cerebro un mecanismo que puede patinar o bien se le puede soltar algún tornillo y descomponerse. En Costa Rica, cuando a alguien se le enciende el bombillo y además tiene cargadas la baterías o las pilas, va sobre ruedas, es decir a toda máquina.

El sistema de representaciones corporales incluye variadas zoomorfizaciones y otras figuraciones con base en elementos naturales en expresiones tales como: "corazón de piedra o hielo", "fuego en la mirada", "mano de hierro" o "pies de plomo". Igualmente, el cuerpo es representado de manera axiológica a través de metáforas de orientación donde la cabeza es el poder y los pies el soporte; el trasero es lo inmundo y lo negado. De este modo "quedar como un trasero" es "pelársela" es decir, quedar muy mal ante otro u otros. Existen además partes nobles e innobles; e igualmente, marcas agoreras, como levantarse con el pie izquierdo versus ser la mano derecha de alguien poderoso.

En el discurso amoroso, se construye un sistema de elogios o piropos que recurren a la comparación para exaltar detalles físicos, especialmente de la mujer. Bien se podría dedicar un estudio completo para el análisis de la picardía popular en relación con este tema, donde la ambigüedad y la comparación son recurrentes, como en este ejemplo: "Quisiera ser ardilla para comerte, Bellota". A Joaquín Salvador Lavado (Quino), en una de sus viñetas le llama la atención las exageradas comparaciones populares de exaltación de la belleza femenina: los labios de fresa, los dientes de perla, el pelo de seda y los ojos de esmeralda. El personaje valora lo difícil que es conseguir estos complicados atributos y opta por renunciar a su amada y buscar otra posiblemente más real.

En el trabajo que presento interesan especialmente las metáforas asociadas a lo vegetal y lo culinario. En este sentido, es posible reactivar el Vertumno de Arcimboldo con base en la esfera del habla popular y sus representaciones en el ámbito literario.

En el contexto próximo del habla popular costarricense cuando alguien es "un fresa", es porque muestra modales muy refinados. Ser un camote o un mozote se asocia a comportamientos de poca inteligencia emocional. Ser un rábano o un pepino significa homosexual, y "ser pura tusa" implica ser débil o incapaz de sostener lo que dice. "Parecer una piña mal pelada" es abrir mucho los ojos sobre todo un hombre frente a una mujer y "pelarse el nance" implica pelarse el trasero, es decir hacer el ridículo. De acuerdo con Annette Calvo, las expresiones alusivas al cuerpo son abundantes, pero no todas, especialmente las que tienen relación con el tabú, están recogidas en los glosarios existentes (Calvo 2010). Sin embargo, la dinámica de estas construcciones no suele ser fija y por lo tanto el ritmo de incorporación y caducidad de estas metáforas requieren de actualización permanente.

$\mathrm{Si}$ consideramos el cuerpo por partes, es aceptado en Costa Rica que la cabeza es el ayote y quien es muy inteligente tiene coco o es muy pipa. En cambio al que carece de inteligencia le falla el maní, el frijol o el garbanzo. Los ojos son guayabas. Los dientes son mazorcas. El trasero es el culantro y las piernas, si son blancas, son yucas o palmitos. Si es mujer, la boca puede ser un caramelo y las mejillas dos tomates. Los senos, dependiendo del tamaño son melones, toronjas o limones y la vagina es una empanada o panocha. Si es un hombre posiblemente la barriga sea un chiverre y el pene, un banano. Los testículos son jocotes, coyoles o lo más común un par de huevos.

Estas referencias son solo una aproximación a modo de ejemplo que podrían servir como punto de partida para un estudio lingüístico o pragmático más exhaustivo. Sobre el 
tema del léxico tabú asociado a lo genital existen varios estudios lingüísticos que permiten establecer diferencias geográficas y sociales. En Costa Rica quien, más ha trabajado este tema es Annette Calvo, quien en el estado de la cuestión de esta temática encontró que:

Las investigaciones relacionadas con la sociolingüística han sido las de mayor impacto, ya que introducen el contexto y la variación lingüística como elementos que aportan una visión más funcional de los factores que determinan el uso del tabú lingüístico. (Calvo 2011: 138)

Sin embargo, asegura Calvo, recientemente también hay investigaciones que abordan los campos semánticos y trabajan procesos de evasión lingüística, así como las metáforas. En nuestro caso, interesa seguir un camino más semiótico y determinar la presencia y significación de estas representaciones corporales en otros discursos, especialmente en el literario.

En este sentido, este sistema de representaciones corporales va más allá del tabú genital y tiene al menos tres funciones básicas: 1) la caricaturización que procura ridiculizar el cuerpo en metáforas tales como el chiverre o el "platanazo" (homosexual); 2) la metáfora gastronómica amatoria o erótica como en "bomboncito" o "panocha" y 3) las figuraciones generales como por ejemplo: "ponerse como un tomate" en alusión al color del ruborizado o "estar como agua para chocolate" en referencia a la sangre que hierve, ya sea por enojo o alguna otra emoción fuerte como podría ser la excitación.

\section{Plato fuerte: La metáforas del cuerpo en los Cuentos de mi tía Panchita}

En 1913, en sintonía con la Revista Infantil Selerín y otros impresos de la época Carmen Lyra (María Isabel Carvajal Quesada, 1887-1949), inicia el proyecto de actualizar cuentos folclóricos para niños. Poco a poco las narraciones van dando forma a un libro titulado Cuentos de mi tía Panchita, publicado en 1920 e ilustrado por Juan Manuel Sánchez.

Hoy estos cuentos forman parte del canon literario costarricense y la crítica literaria nacional, así como la historiografía, no dudan en ubicarlos como uno de los textos fundacionales de literatura infantil (Bonilla 1967; Sandoval 1978; Pérez 1984; Ferrero 1985; Dobles 2003, así como Quesada y Vásquez 2011, entre otros).

Sin embargo, tal y como sucede en El Quijote de la Mancha, sorprende la poca visibilidad que ha tenido el intertexto gastronómico en estos cuentos. Recientemente, en El Quijote se ha empezado a estudiar este discurso y se ha descubierto que es una importante veta fundacional de la relación entre literatura y gastronomía ${ }^{1}$ (Díaz 2005). En Cuentos de mi tía Panchita, existe igualmente una amplia referencialidad culinaria, la cual resulta fundacional de este tema en la literatura costarricense. Los recetarios populares que atraviesan el texto, sin embargo, no han sido estudiados con cuidado, posiblemente porque los estudios se han dedicado principalmente a explicar la correlación entre la tradición folclórica y la función infantil. (Rojas 2005; Quesada y Vásquez 2011, entre otros).

En estos cuentos, Carmen Lyra rescata el código oral e inserta expresiones populares entre las que destacan estas referencias culinarias. Esta estrategia discursiva resulta verosímil pues la narradora es una supuesta tía de la autora y cuenta estas historias en el ambiente de la cocina, donde pasa la mayor parte del día. De acuerdo con Margarita Rojas: 
Tía Panchita es una mujer bajita y risueña, habitante diaria de la cocina y habladora. Cuenta lo que sabe y por esto las metáforas gastronómicas y las referencias culinarias son abundantes. De acuerdo con la presentación que hace Carmen Lyra, esta anciana:

\begin{abstract}
Hacía mil golosinas para vender, que se le iban como agua y que tenían fama en toda la ciudad. En el gran armario con puertas de vidrio que había en el pequeño corredor de la entrada, estaban los regalos que sus manos creaban para el paladar de los josefinos: las cajetas de coco y de naranja agria más ricas que he comido en mi vida; quesadillas de chiverre que muchas veces hicieron flaquear mi honradez; muñequillos y animales fantásticos de una pasta de azúcar muy blanca que jamás he vuelto a encontrar; bizcocho y tamal asado que atraían compradores de barrios lejanos: del Paso de la Vaca y de la Soledad; en frascos de cristal estaban sus perfumados panecillos de cacao Matina con los que se hacía un chocolate cuyo sabor era una delicia, y que coronaba las tazas con un dedo de rubia espuma. (Lyra 2012: 18)
\end{abstract}

Gracias a esta presentación y a las alusiones culinarias que, como veremos, son constantes en sus relatos, Carmen Lyra se adelanta a la saga de la literatura del tema culinario que se desarrolló en América Latina en la segunda mitad del siglo XX. Recordemos que una de las primeras novelas que utiliza el discurso gastronómico en nuestro continente es en Gabriela clavo y canela (1958) del brasileño Jorge Amado y que en su obra cumbre Doña Flor y sus dos maridos, Florípedes Paiva Guimaráes tiene una escuela de cocina llamada Sabor y Arte. Es aquí donde Vadinho, quien pronto será el primer marido de la protagonista, trastoca este significado y con genialidad seductora funde el paladar y el eros, gracias la ingeniosa deconstrucción: "quiero saborearte". En 1989, con su novela Como agua para chocolate, la mexicana Laura Esquivel va más allá de lo culinario-erótico y convierte el motivo gastronómico en un código de poder e identidad femenino.

En Costa Rica, este código culinario es poco recurrente, aunque cuenta con algunos ejemplos. Inicia con el cuento “QQuiere usted quedarse a comer?" (1896) de Manuel González Zeledón y recientemente aparecen algunas alusiones como en el título Hombres en escabeche (1999), obra de teatro de Ana Iztarú, y más explícitamente en la novela D. Juan de los manjares (2012) de Rafael Ángel Herra.

En Costa Rica, Leonardo Sancho es uno de los investigadores que más ha abordado la relación cocina y literatura. De acuerdo con sus investigaciones:

\footnotetext{
[...] a lo largo de la historia de la literatura, de la gastronomía y de la cultura se ha dado un entrelazamiento del arte culinario con el arte literario; es decir, al formar parte del discurso literario, la gastronomía o la culinaria evidencian las prácticas de cada cultura desde uno de los espacios más íntimos, la cocina, donde no entran todas las personas convidadas pero desde donde sí salen hacia los espacios sociales los guisados, los platillos y las viandas para agasajar al "otro" y con ello sellar los lazos y darse a conocer (Sancho 2011: 70)
}

Es en este espacio doméstico, vedado al público masculino adulto, donde tía Panchita recurre a lo culinario como estrategia narrativa. Los cuentos giran alrededor del fogón y esto coincide con las constantes referencias a platos y productos alimenticios, la mayoría propios de la dieta costarricense. Uvieta comparte su bastimento y consigue un saco del que salen todos los manjares. Juan Cacho comparte su pan y el salchichón, y recibe una servilleta de virtud que le depara un largo menú de delicias típicas: un pichel lleno de postrera amarillita, un cerro de tortillas con queso, bollos de pan dulce con corteza morena y jalea de membrillo y de guayaba, entre otros productos. La mica es una cocinera de chuparse los dedos. La cucarachita mandinga prepara el arroz con leche y hace caer al goloso de su Ratón Pérez: "Por jartón, por jartón, por jartón se cayó en la olla" (Lyra 1936: 107). En la casita de las torrejas, la bruja quiere cocinar a los niños que atrapa y los engorda para preparar una fritanga. En el cuento "La negra y la rubia", el príncipe 
encuentra a la rubia en una olla "todita tiznada y haciendo cucharas" (Lyra 1936: 139). La saca de la olla y ahí mismo le propone matrimonio. En los cuentos de tío conejo, los personajes tienen huertas con todo tipo de verduras y son desmedidamente glotones. Por un queso, tío Coyote se bebe el agua de un charco con el convencimiento de que es suero. Tío Conejo Comerciante va de casa en casa ofreciendo vender una fanega de maíz y otra de frijoles y cada anfitrión le ofrece algún bocadillo tradicional. Finalmente, el fogón es el espacio donde cada uno los personajes engañados corren a esconderse para librarse de su depredador.

En estos Cuentos de mi tía Panchita, el cuerpo es metáfora y metonimia de vinculaciones culinarias. La combinación sintagmática está presente en la escena donde la Mica se hecha comida en el cuerpo y cuando los bocadillos caen al suelo aparecen convertidos en joyas; en cambio sus concuñadas al hacer lo mismo hacen el ridículo:

\footnotetext{
Durante la comida, sus concuñas, que no le perdían ojo, vieron que la princesa se echaba entre el seno, con mucho disimulo, cucharadas de arroz, picadillo, pedacitos de pescado y empanadas. Por imitar hicieron lo mismo. Después hubo un gran baile. Cuando empezaron a bailar, la princesa se sacudió el vestido y salieron rodando perlas, rubíes y flores de oro. Las otras creyeron que a ellas les iba a pasar lo mismo y sacudieron sus vestidos, pero lo que salió fueron granos de arroz, el picadillo, los pedazos de carne y las empanadas. Los reyes y sus maridos sintieron que se les asaba la cara de vergüenza. (Lyra 1936: 84)
}

Esta última imagen "asarse la cara de vergüenza" conecta con el sistema metafórico del habla cotidiana que ya habíamos visto en la primera parte de este artículo. Se trata de expresiones populares y otras creadas por la autora, cuya función es comparar el cuerpo o partes de este con productos vegetales, culinarios y concomitantes.

Así, a Juan el de la carguita de leña también se el asa cara de la vergüenza (Lyra 1936: 46); la princesa hace cucharas y luego llora: "Hasta fea estaba, ella que era tan preciosa, de tanto llorar: con los ojos como chiles y la nariz como un tomate" (Lyra 1936: 47). El tomate por su color, como ya habíamos visto alude al rubor de la vergüenza, pero aquí se utiliza para pintar la nariz y en el cuento "La negra y la rubia" se aplica para describir el color de los ojos de la niña rubia, que se le pusieron así debido al humo de la leña verde con la que esta cocinaba. Estos mismos ojos, al inicio del cuento son como "ver dos rodajitas que se le hubieran sacado al cielo. Y sobre todo, sangrita ligera y buena que daba gusto"(Lyra 1936: 131).

Los vegetales son referentes de belleza, especialmente en relación con las mujeres. Así en el cuento "El cotonudo", la princesa de la que se enamora el protagonista "era como ver el sol de rubia y en la que cada hebra era crespa como un quelite de chayote" (Lyra 1936: 88). En el caso de la Mica, cuando esta se transforma en princesa, sus dientes parecían pedacitos de cuajada (Lyra 1936: 83).

En el caso de los hombres, la belleza no está en lo físico, sino en la presentación física. Por esta razón, en el Cotonudo "A la princesa le llamó la atención aquel joven tan galán vestido pobremente, pero tan limpio que parecía un ajito" (Lyra 1936: 88). Sin embargo, en el decir de la gente, cuando la princesa decide casarse con él: "¡Siempre el peor chancho se lleva la mejor mazorca!" (Lyra 1936: 95). Este atípico enamoramiento pone furioso al rey que "se puso como agua para chocolate" (Lyra 1936: 95).

La relación establecida entre la comida y el cuerpo en el caso de estos cuentos excluye la función erótica que es bastante explícita en otros textos literarios, como en el citado Doña Flor y sus dos maridos. Esto es lógico pues el público meta es infantil; sin embargo, la escena del príncipe que saca de la olla a su futura esposa posibilita la imagen de la coincidencia comida igual cuerpo. Es decir, al igual que el lobo de Caperucita Roja, este príncipe es un hambriento, pero el tipo de hambre no se explicita y en la dimensión superficial, lo que se ve es 
el ideal del caballero romántico que rescata a una pobre niña. Pero el canibalismo, propiamente, aflora sin máscaras en la acción perversa de la bruja de las torrejas, quien engordó, a punta de desperdicios, a los niños con la clara intención preparar con ellos una fritanga. "Como estaban tan flacos que parecían fideos, la bruja les dijo que no se los comería, pero que los iba a engordar como a unos chanchitos, para darse cuatro gustos con ellos" (Lyra 1936: 121). Más perverso aún resulta la imagen de los personajes devorados por otros en los cuentos de tío coyote. Oculta tras la máscara de la zoomorfización en el cuento de "Tío Coyote Comerciante", los personajes se comen unos a otros sin el más mínimo asomo de culpa.

En el siguiente cuadro, se sistematiza este proceso de metaforización. Incluye vegetales y otros productos comestibles, así como la concomitanci; por ejemplo: hacer cucharas. Además de las comparaciones físicas, el sistema admite expresiones emotivas.

\section{Referentes gastronómico corporales en los Cuentos de mi tía Panchita}

\begin{tabular}{|l|l|}
\hline $\begin{array}{l}\text { Referente } \\
\text { Elemento A }\end{array}$ & $\begin{array}{l}\text { Figuración } \\
\text { Elemento B }\end{array}$ \\
\hline Cuerpo Feminino & Mazorca \\
\hline Pelo crespo & Quelite de chayote \\
\hline Nariz & Tomate \\
\hline Ojos & Chiles, Tomates, Rodajas \\
\hline Dientes & Cuajadas \\
\hline Cuerpos delgados & Fideos \\
\hline Limpieza corporal & Ajito \\
\hline Enojo & Agua para chocolate \\
\hline Vergüenza & Asarse la cara \\
\hline Llanto & Hacer cucharas \\
\hline
\end{tabular}

Este sistema funciona como una especie de cronotopo asociado a la comida y que llamaré cronotopo arcimboldiano, pues los personajes son comensales y al mismo tiempo comestibles. El espacio es la cocina: el fogón y la olla; es la mesa: el plato y la comida, y el tiempo es la recolecta de la leña, la hora de preparar los alimentos y el momento de degustarlos en la mesa. En el centro de esta escena, hay un bodegón en forma de ser humano, hecho de elementos culinarios. El personaje de este cronotopo se convierte en lo que come, y al mismo tiempo, en consecuencia, al ser ingrediente gastronómico es igualmente comestible. Es la hora de la comida, pero también es la hora de gozar el cuerpo del otro. La transformación es deseo: antropofágico y libidinoso. En Los cuentos de mi tía Panchita, es mucho más claro el deseo antropofágico que el segundo, pero las idealizaciones de la belleza femenina ofrecen atisbos eróticos y por lo tanto también se sugiere la posibilidad de devorar el cuerpo como objeto. Esto se puede constatar en la imagen de la mazorca mujer que se come el cerdo varón o la niña rubia que encuentra el príncipe en la olla y la convierte en su mujer.

\section{Postre o comentario postrero: Los arquetipos de la degustación corporal}

La conexión comida-cuerpo es sin duda arquetípica y se funda en la propia condición vital del amamantamiento y el placer oral. El cuerpo de la madre es simbólicamente comestible y por lo tanto clave para la sobrevivencia. Por esta razón, el acto de comer de la madre instala la 
primera clave para comprender la multiplicidad de metáforas antropofágicas y culinario sexuales que tiene la cultura. De hecho, en el mito fundador más conocido en Occidente, el activador clave es la tentación de comer el fruto prohibido. Las representaciones pictóricas que datan de la Edad Media muestran a una mujer ofreciendo una manzana. Ella está desnuda y ella misma es la tentación. Adán muerde la manzana, pero en lo no dicho, es el cuerpo de Eva lo que seduce.

En la jerga cotidiana costarricense, esta correlación se establece claramente con el piropo "rica" o "rico", expresión que traslada el placer del paladar a la percepción del cuerpo sexi o bien dotado.

Estamos entonces en el terreno de las metáforas sinestésicas, donde las sensaciones auditivas, visuales, olfativas, gustativas y táctiles giran alrededor del cuerpo. La degustación es total: El cuerpo suena, es grato a la mirada, expele olores, sabe y es palpable o lo que es etimológicamente equivalente, palpitable.

De acuerdo con Adolfo Váquez Rocca

\begin{abstract}
En nuestra cultura se privilegia el sentido de la vista, mientras que la aproximación olfativa, táctil y acústica -los olores, las texturas y los sonidos- están totalmente proscritos. Lo que ha ocurrido es que la sociedad occidental ha privilegiado la distancia física y la mirada por encima de cualquier otro sentido, hasta tal punto que nuestras experiencias corporales están reducidas, en la mayoría de los casos al sentido de la vista. (2008: 3)
\end{abstract}

Considero que esta postura de Vásquez Rocca no es del todo precisa, pues el olfato, la vista y el oído gozan de mayor privilegio, dado que no encuentran tantas censuras en el discurso moral oficial, como sí lo encuentra el gusto y el tacto. Esto es evidente en la moral cristiana donde estos dos últimos sentidos son los únicos susceptibles de pecado capital. El gusto lleva a la gula y el tacto a la lujuria. Esta estrecha vinculación entre ambos sentidos permite además constatar esta diada degustación-tacto como aliados de perversión. En cambio, aunque el voyerismo que implica oír y ver es censurado, no tiene un estatus tan altamente pecaminoso.

Comer y tocar son entonces los dos delitos más importantes de esta moral cristiana. Esta axiología también está presente en Los cuentos de mi tía Panchita, pues es la gula lo que seduce a Tío Coyote cuando bebe el agua de un charco con el convencimiento de que al tomar el supuesto suero podrá conseguir el enorme queso que se ve en el fondo. En su apetito desmedido no sabe que es víctima de las perpetraciones de Tío Conejo, quien logrará matarlo haciendo que se estalle debido a la cantidad exagerada de agua "suero" que se bebió. La gula entonces es su desgracia y de este modo queda claro el castigo. Igual sucede con los niños que se aventuran a comer torrejas. Como consecuencia casi son devorados por la bruja. Otro de los castigados es el ratón Pérez, quien por glotón cayó en la olla con arroz con leche y se murió. La comida es placer, pero la desmesura implica castigo y esta la moraleja tácitas de estas narraciones.

En resumen, los personajes de estos cuentos, convertidos en manjares, son degustados doblemente. Por un lado, son objeto del deseo de otros personajes, pero también son deliciosos al sibarita de la palabra, es decir al lector que gusta de estos temas. Los Cuentos de mi tía Panchita es banquete para aquellos interesados en el tema de la cocina o en esta curiosa figuración culinaria de los cuerpos arcimboldianos. Para quienes están interesados en este tema: la mesa está servida.

\title{
Notas
}

1. Uno de los textos que aborda este tema es La cocina del Quijote de Lorenzo Díaz. (2005. Madrid: Alianza Editorial). Este texto investiga las referencias gastronómicas del Quijote y elabora un recetario con base en esta investigación. 


\section{Bibliografía}

Bonilla Baldares, Abelardo. 1984. Historia de la literatura de costarricense. San José: Stvdivm.

Diaz, Lorenzo. 2005. La cocina del Quijote. Madrid: Alianza.

Dobles Rodríguez, Margarita. 2003. Literatura infantil. (2 reimpresión). San José: EUNED.

Ferrero Acosta, Luis. 1958. Literatura infantil costarricense. San José: Ministerio de Educación Pública.

Calvo Shadid, Annette. 2011. "Sobre el tabú, el tabú lingüístico y su estado de la cuestión”. Káñina, Revista de Artes y Letras. 35 (2): 121-145.

Lyra, Carmen. 1936. Los cuentos de mi Tía Panchita. San José: Imprenta Española.

Pérez Yglesias, María. 1985. "La literatura infantil en Costa Rica (1900-1984), y el mundo mágico de Adela Ferreto". Káñina, Revista de Artes y Letras. 9 (1): 101-118.

Quesada Villalobos, Patricia y Vásquez Vargas Magdalena. 2011. "La literatura infantil en Costa Rica: aportes y ausencias desde la historiografía literaria”. Revista Comunicación. 20 (1): 32-38.

Rojas, Margarita. 2005. "Las aventuras de tío conejo en libros y revistas Costarricenses de la primera mitad del siglo XX". Revista de Filología y Lingüística. 31 (extraordinario): 105-113.

Sancho Dobles, Leonardo. 2011. "Comerse un cuento: A propósito de identidades, literatura y gastronomía”. Revista Herencia. 24 (1 y 2): 63-71.

Vásquez Rocca, Adolfo. 2008. "Las metáforas del cuerpo en la filosofía de Jean-luc Nancy. Nueva carne, cuerpo sin órganos y escatología de la enfermedad". Nómadas. Revista Crítica de Ciencias Sociales y Jurídicas. 18 (2). http:// http://pendientedemigracion. ucm.es/info/nomadas/18/avrocca2.pdf 